\title{
Esquema de ISO 27001 Sistema de Gestión de la Seguridad de la Información
}

\author{
Scheme of ISO 27001 Information Security Management System
}

\author{
Clara B Rivera-Guerrero ${ }^{a}$, Ana M Felipe-Redondo ${ }^{b}$, Felipe J Nuñez-Cárdenas ${ }^{c}$
}

\begin{abstract}
:
Currently, information has been transformed into an intangible asset that requires guaranteeing its integrity, availability and confidentiality. The ISO 27001 Information Security Management System helps to manage the security of assets such as financial information, intellectual property, details of employees or customers, among others, through the requirements documented in the chart, the standard has been updated and the 2013 version is in force.
\end{abstract}

Keywords:

ISO 27001, SGSI, information asset

Resumen:

Actualmente la información se ha transformado en un activo intangible que requiere de garantizar su integridad, su disponibilidad y confidencialidad. La ISO 27001 Sistema de Gestión de la Seguridad de la Información contribuye a administrar la seguridad de los activos como la información financiera, propiedad intelectual, detalles de los empleados o los clientes, entre otros, a través de los requisitos que se documentan en el gráfico, la norma ha pasado por actualizaciones siendo vigente la versión 2013.

Palabras Clave:

ISO 27001, SGSI, Activo de información

\section{Introducción}

El esquema que se muestra describe e identifica los "debes" de la Norma, así como la "información documentada", tiene como propósito que a través de una lectura rápida se pueda tener un panorama claro y completo de los requisitos que se deben cumplir.

La norma cuenta con diez requisitos, los tres primeros no son auditables y corresponden Alcance, Referencias Normativas y Términos y Definiciones el gráfico no los considera. Se incluyen los criterios del 4 al 10: Contexto de la organización, Liderazgo, Planificación, Apoyo, Operación, Evaluación del desempeño y Mejora.

Descripción gráfica

En el gráfico se visualiza cada requisito con sus requerimientos asignándoles un color, las flechas indican la información que se debe documentar, misma que también es colocada de un solo color.

\footnotetext{
a Alumna de Ingeniería de tecnología e Información de la Universidad Tecnológica de la Huasteca Hidalguense, Email: riveragcb@ gmail.com

Maestro de tiempo completo de la Universidad Tecnológica de la Huasteca Hidalguense, Email: ana.felipe@uthh.edu.mx Maestro de tiempo completo de la Universidad Autónoma del Estado de Hidalgo, Email: felipe_nunez@uaeh.edu.mx
} 


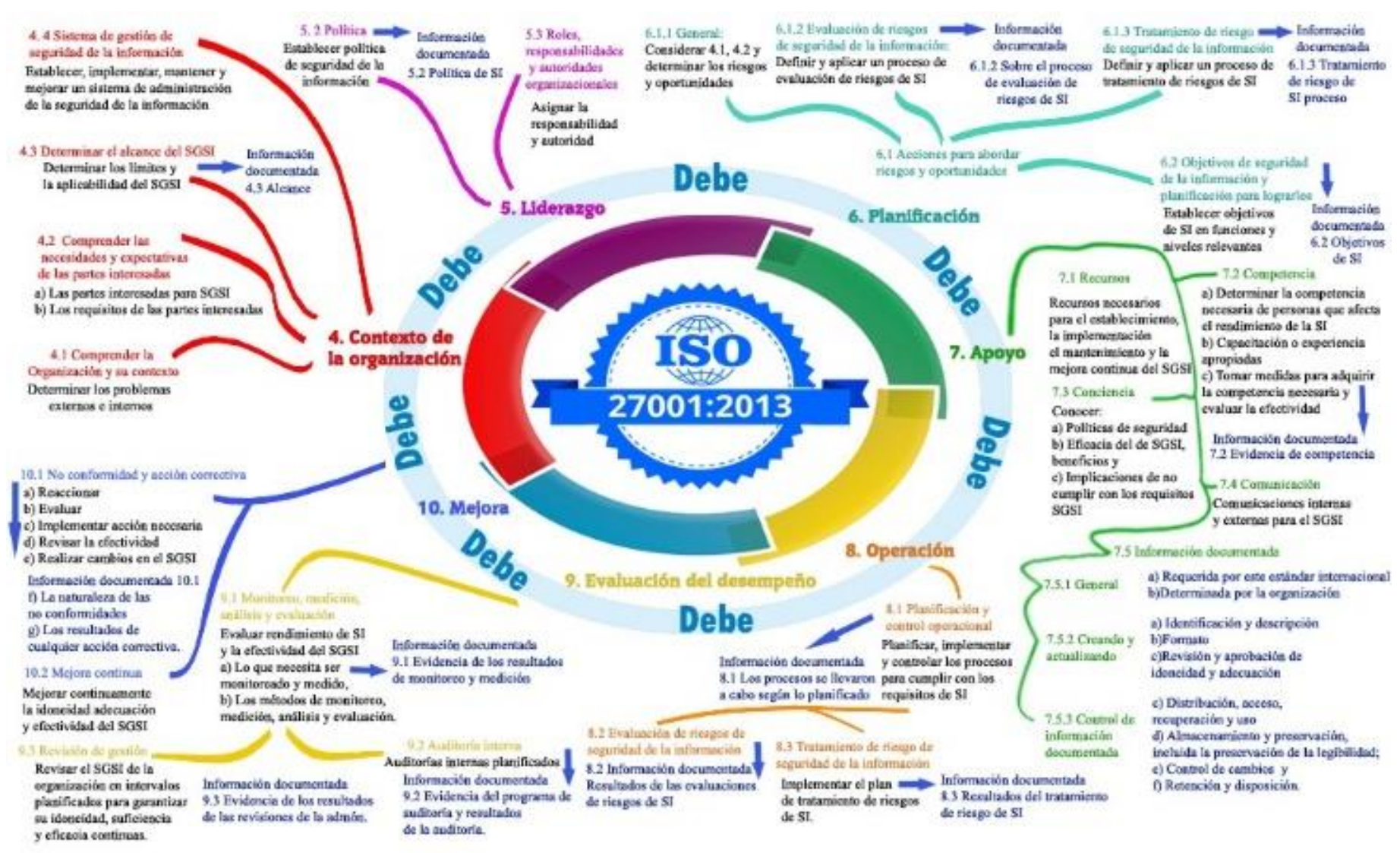

Figure 1. ISO 27001

\section{Referencias}

[1] Bell, D., 1973. The coming of post-industrial society, Basic Books.

[2] ISO/IEC 2013. (2013). Information technology - Security techniques -Information security management systems -Requirements. Second edition. Recuperado de: www.iso.org

[3] Masuda, Yoneji (1980): The Information Society as Post-Industrial Society (The World Future Society, Tokyo, IIS, Washington D. C.) 